\title{
Analysis of the efficiency of low noise barrier using STERED material
}

\author{
Peter Zvolenský ${ }^{1}$, Alžbeta Pultznerová $^{2, *}$, and Juraj Grenčík ${ }^{1}$ \\ ${ }^{1}$ University of Žilina Faculty of Mechanical Engineering, Univerzitná 8215/1, 01026 Žilina, Slovak \\ Republic \\ ${ }^{2}$ University of Žilina Faculty of Civil Engineering, Univerzitná 8215/1, 01026 Žilina, Slovak \\ Republic
}

\begin{abstract}
When reducing noise, especially around the so-called corridor railway tracks, but also at the hump yard, the most suitable structure and composition of acoustic barrier materials are searched. It is also issue of the durability and stability parameters of the acoustic properties of the materials used for different climatic conditions. In the paper the experimental verification of the required and the expected acoustic properties of the newly-designed low acoustic barriers exposed to real noise from the hump yard are.
\end{abstract}

\section{Introduction}

As most of the railway lines in Slovakia were built in the $19^{\text {th }}$ and early $20^{\text {th }}$ century, the problem of excessive noise and the measures to its reduction were not considered in their design and construction. Nowadays there is much higher concentration of traffic noise and by the modernization of railway lines the track speed is increasing to $160 \mathrm{~km} \cdot \mathrm{h}^{-1}$, which results in the increase of noise exposure. So the issue becomes the priority requirement and appropriate proposals for its reduction are needed.

\section{Propagation and noise transmission}

The sound waves propagate in the air in all directions from the noise source, while the shape of the acoustic field is being influenced by various influences. In particular:

- the directional radiation characteristic of the source,

- the acoustic properties of the environment in which the emitted sound energy spreads,

- the barriers to the noise propagation path.

Sound field propagation and sound waves attenuation depends on:

- the distance of the recipient,

- the meteorological conditions,

- the surface and area of the site.

* Corresponding author: alzbeta.pultznerova@,fstav.uniza.sk 


\section{Methods to reduce noise}

From construction - technical point of view, the noise reducing measures may be:

- active,

- passive.

In the paper we will focus on the passive reduction of noise.

\subsection{Passive measures on the noise propagation path}

Acoustically sufficient sound reducing barriers, which are built on the sound wave propagation path, reduce the sound pressure level behind the obstacle by creating a sound shadow. Solutions for creating obstacles to noise propagation such as:

- noise barriers, characterized by the difference in height between the height and length on one side and the thickness on the other,

- material objects whose height, length and thickness are about the same (houses, garages, warehouses, etc.)

- earthworks,

- vegetation.

By appropriately combining these noise barriers, their synergistic attenuation effect can be achieved and their better integration into the urbanized environment can be achieved.

\subsection{Noise barriers}

Noise barriers are built in connection with the upgrading of railway corridors based on noise studies and detailed calculations of isophones. Their necessity results from the proposed increase in track speed in the SR (Slovak Republic) on modernized sections of the tracks to $160 \mathrm{~km} \cdot \mathrm{h}^{-1}$.

Sound energy propagates from the source to the noise barrier (NB) in five ways, as shown in Figure 1 [1]:

1 - passes through the NB to the recipient,

2- it propagates around the top edge of the NB (diffraction)

3 - is reflected back from the surface of the NB,

4- is absorbed by the NB (absorption),

5 - passes at the ends of the noise barrier to the recipient.

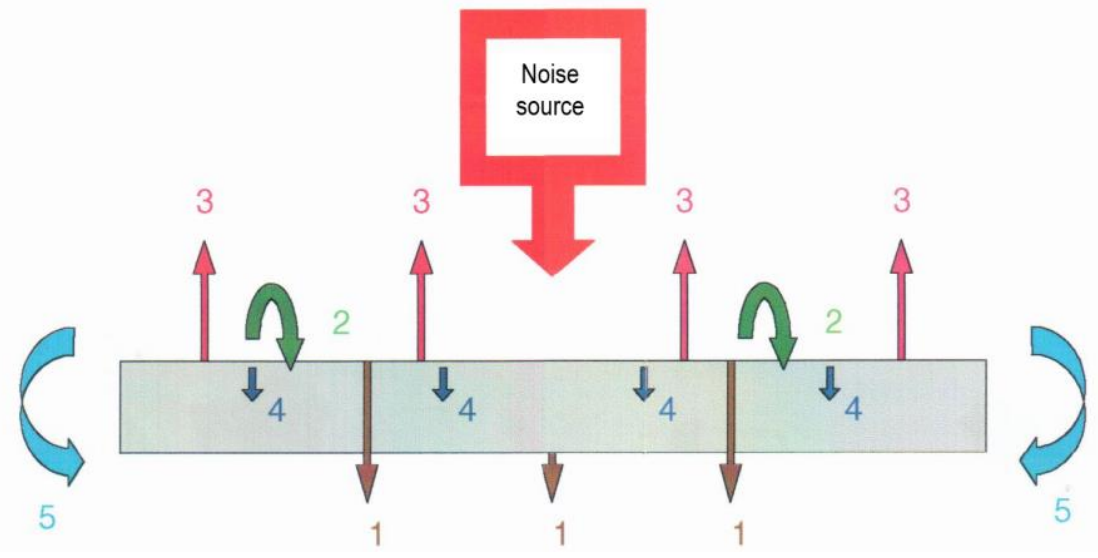

Fig. 1. Sound energy acting on NB [own research] 
The effectiveness of the noise barrier depends on the structural elements, material, shape, height, length and location in the exterior.

\subsection{Acoustic performance of noise barrier [2]}

The location of the noise barrier can significantly reduce the intensity of the direct beam $\mathrm{L}_{\mathrm{p}}$, tr (Figure 2).

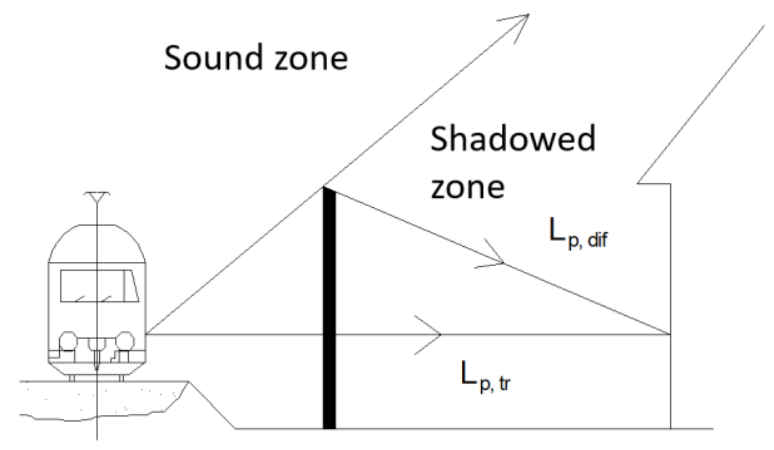

Fig. 2. Schematic figure of sound transmission for shadowed noise source [2]

Noise barriers must be of a (reasonable) insulation to sound passing through $\left(\mathrm{L}_{\mathrm{p}, \mathrm{tr}}\right)$ so that the a transmissive sound was negligible compared to the diffraction sound ( $\left.\mathrm{L}_{\mathrm{p}, \mathrm{dif}}\right)$. The limit value of the noise transmission contribution to the overall noise level is $0.5 \mathrm{~dB}(\mathrm{~A})$, that is an important beam is the beam that is diffracted downwards from the top edge of the noise barrier $\mathrm{L}_{\mathrm{p} \text {,dif. }}$

\section{Low noise barrier (LNB)}

Studies show that the low noise barrier near the track appears to be less effective because if it's low height. LNB with a reflective surface in some cases even increased the noise levels due to multiple reflections. Only LNB with an absorbent surface have some effectiveness, yet in connection with the absorbent surface at the bottom of the wagons. [2]

Low noise barriers are placed on the subbalast layer at the grade of subgrade surface of the railway track at a distance of $1.730 \mathrm{~m}$ from the track axis. The barrier height is $0.730 \mathrm{~m}$ from the top of the rail, while the top edge of the panel lay as narrowly as possible to the structure gauge of the track. BRENS BARRIER's low noise barrier allows passengers to be evacuated from a rail vehicle, has an outward footpath and a survival space towards to the track. On the side of the rail, the LNB panel is furnished with a noise-absorbing layer made up of recycled materials with an acoustic attenuation min. A3. The parts are laid on the face, the joint is sealed with a rubber profile on one side of the piece. The mutual position of the parts is fixed by the embedded rubber pins. [3]

\subsection{Covering of the LNB}

In the paper, the low noise barrier covering using the STERED material is evaluated. It is a recycled material from the automotive industry and used as a new covering of LNB.

The basic principle of its manufacture is the mechanical reprocessing of the original material. The patent-protected STERED ${ }^{\circledR}$ product is manufactured on the basis of mechanical recycling of synthetic textiles. 
Due to the quality of the input material, there is limited need to add additional additives to the materials. Most of the declared properties are achieved by selecting the basic materials which are used for the production of textile car parts (hygienic safety, chemical resistance and stability, etc.). A binder based on PUR is added to the homogenized STERED S base material. After the chemical reaction, the structure is stabilized, without any released particles to the surrounding environment. The manufacture of the final product of the STERED ID insulation board does not produce any other technological waste.

The STERED ${ }^{\circledR}$ construction material in its basic form of homogenized, shimmer-like shape, STERED S is non-ductile and it features the ability to hold the shape of a particular mold even without the addition of other binders.

\subsection{Measurement of the effectiveness of the low noise barrier}

Measurement was preceded by measurement and recording the noise produced by braking vehicles on rail brake on hump yard in a $7.5 \mathrm{~m}$ distance in free sound field.

Measurement conditions:

Measuring time: 8:00 - 12:30

Weather: partly cloudy, wind $3 \mathrm{~m} / \mathrm{s}$

Measuring temperature: $17^{\circ} \mathrm{C}$

Humidity: $48 \%$

Speaker: 3-band active speaker FBT Verve 110A with processor $400 \mathrm{~W}+100 \mathrm{~W}$ RMS - $128 \mathrm{~dB}$ SPL, with frequency range $12-20000 \mathrm{~Hz}$

After the instrumentation was assembled and the PC turned on, an automatic calibration was performed. The measurement was done by playing the sound record done during the noise measurement on the hump yard when the rail brake was acting in the free space and using two types of barriers of sandwich structure with the STERED material used (Figure $3)$.

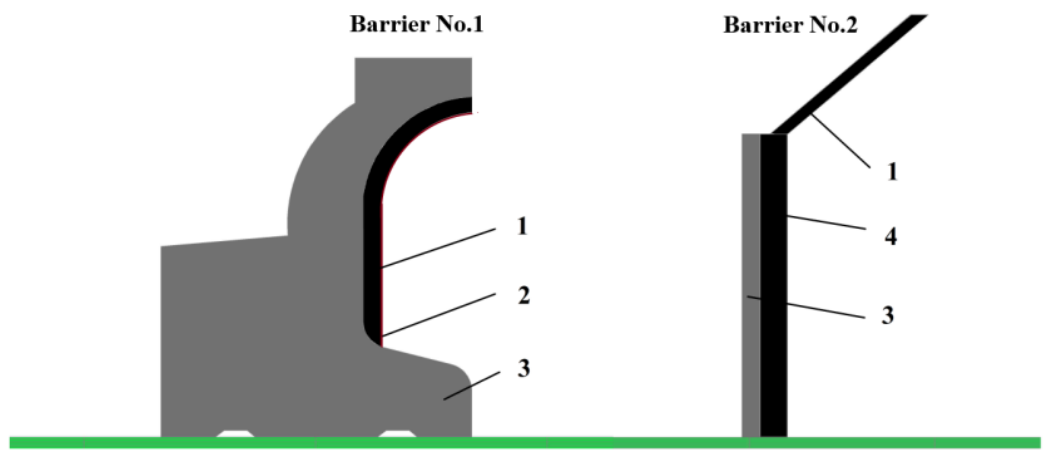

Fig. 3. Structure of designed low acoustic barriers with STERED material [own research]

1 - STERED thickness of B1 $8 \mathrm{~cm}, \mathrm{~B} 25 \mathrm{~cm}$

2 - Rubber thickness of $2 \mathrm{~cm}$

3 - Bearing concrete structure (B2 thickness $8 \mathrm{~cm}$ )

4 - STERED thickness of $13 \mathrm{~cm}$

In order to objectivize the measurement, the loudspeaker was positioned and directed precisely to the center between the walls, and the measuring microphones were directed at the same distance from the source at the both LNB as follows: microphone No. 1 at the distance of $3100 \mathrm{~mm}$ at the height of $500 \mathrm{~mm}$ from the ground; microphone No. 2 at the distance of $4500 \mathrm{~mm}$ at the height of $500 \mathrm{~mm}$ from the ground (which was below the wall 
length) and a microphone No. 3 at the distance of $1400 \mathrm{~mm}$ at the height of $800 \mathrm{~mm}$ from the terrain, which was located in front of the wall (Figures 4 and 5).

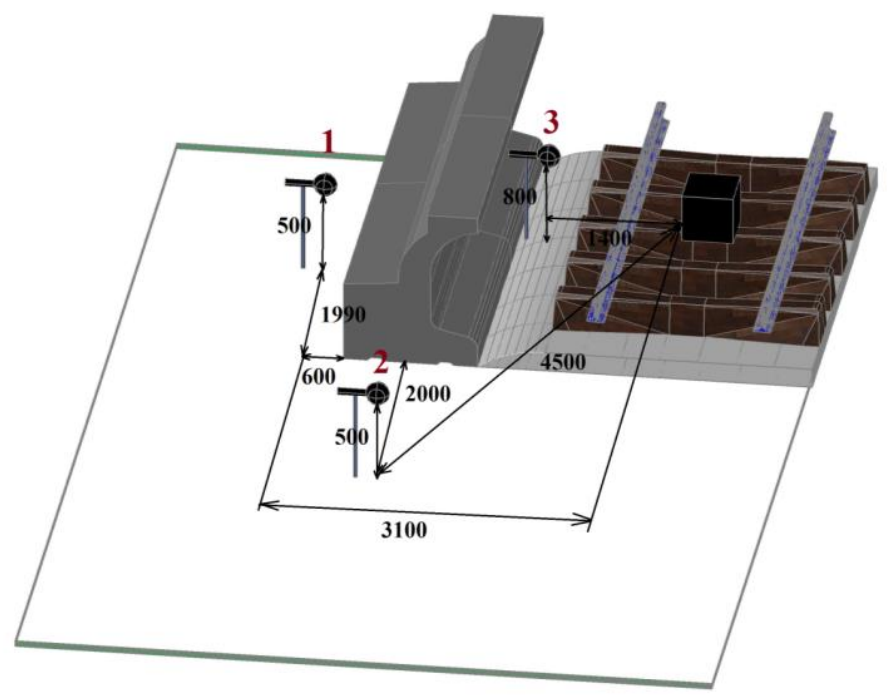

Fig. 4. Microphone layout diagram for LNB B1 [own research]

The height of the both LNBs was the same $-160 \mathrm{~cm}$. When detecting the acoustic properties of the walls, they had to be considered for their minimum length, so not only one barrier was used during measuring, but two of them were firmly connected of the same type with a total length of $398 \mathrm{~cm}$.

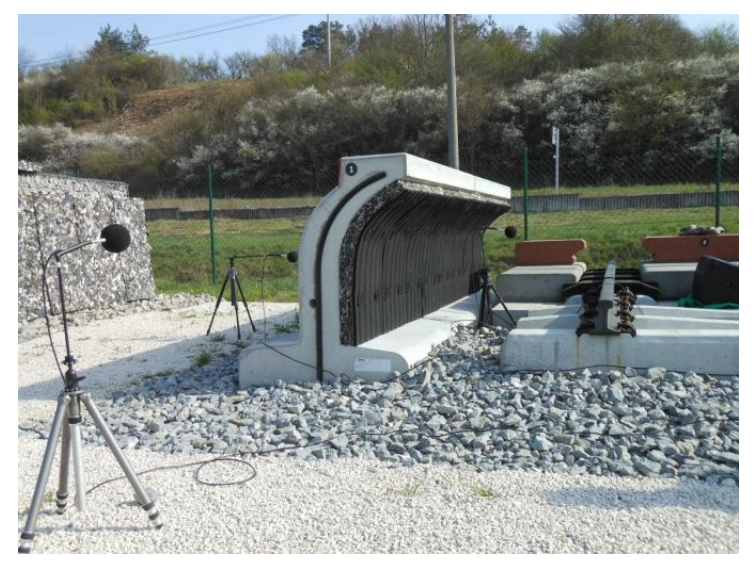

Fig. 5. Photo form the measurement of LNB No. 1 [own research]

As it is evident from Figure 6, the noise level drop from the record No. 1, which was recorded on the hump yard at B1, ranged from 20 to $32 \mathrm{~dB}$ (A). This is the medium to high degree of sound reduction of this wall. 


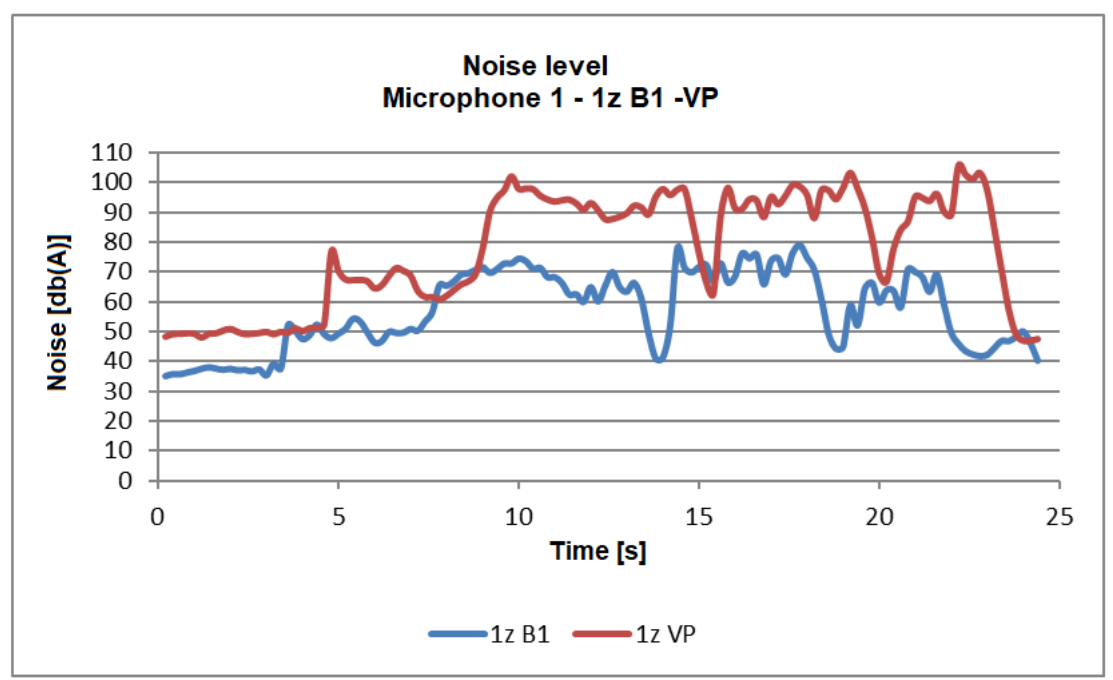

Fig. 6. Measurement of the noise level record No. 1, microphone No.1 in the free field and after the attenuation with the LNB B1 [own research]

In the frequency analysis (Figure 7) it can be seen that at low frequencies from $0-100 \mathrm{~Hz}$ the sound reduction is very low, about $2 \mathrm{~dB}$ from $100-1000 \mathrm{~Hz}$ is approximately $15 \mathrm{~dB}$ and at higher frequencies already from about $2000 \mathrm{~Hz}$ is high (approx. $40 \mathrm{~dB}$ ). The frequencies from $17000 \mathrm{~Hz}$ from record No. 1 the LNB B1 could completely eliminated.

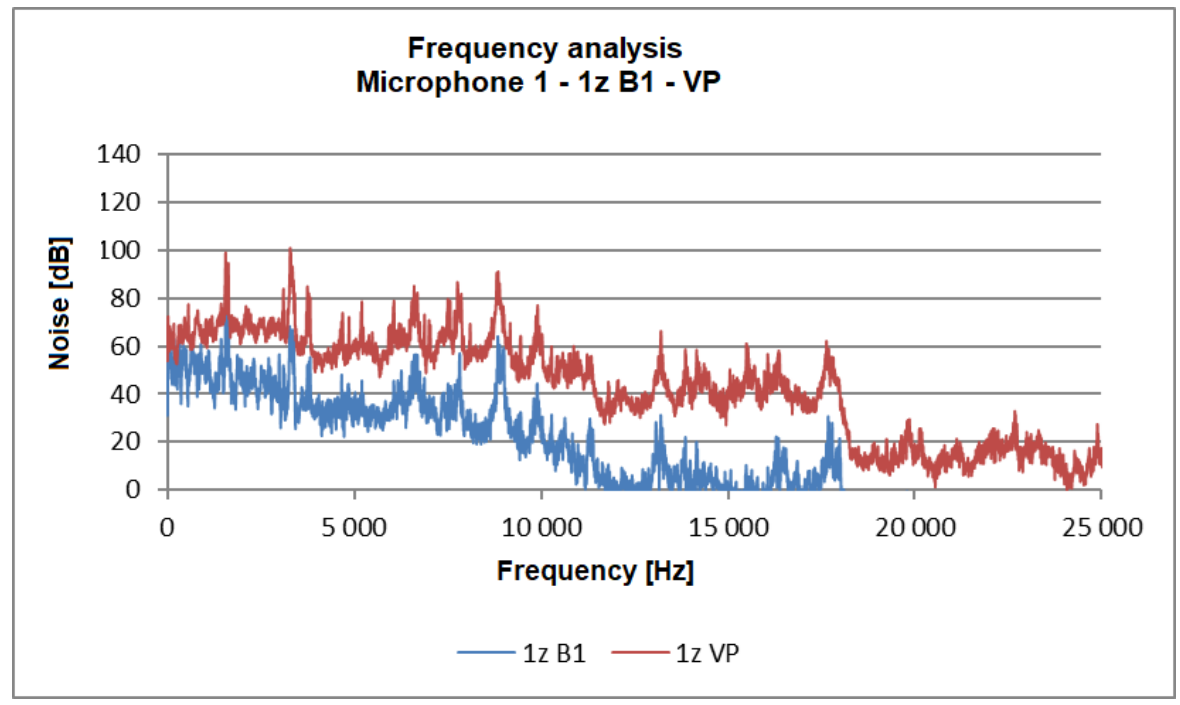

Fig. 7. Frequency analysis of noise recording No.1, microphone No.1 in the free field and after attenuation by LNB B1 [own research] 
Fig. 8. Microphone layout diagram for LNB B2 [own research]

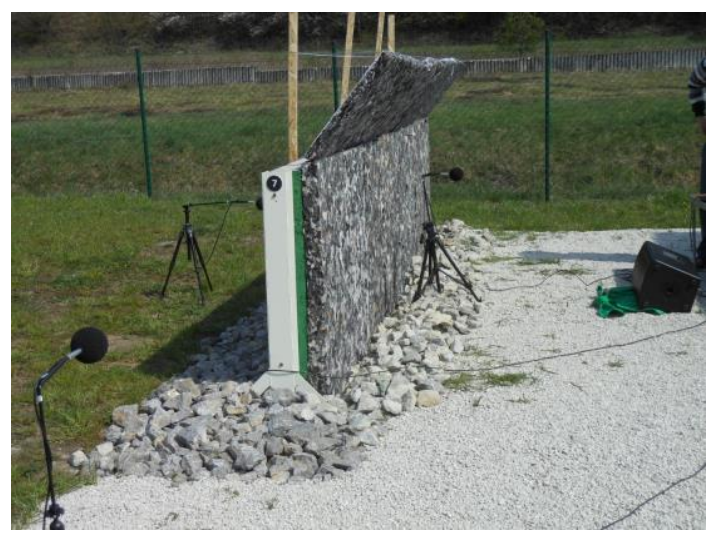

Fig. 9. Photo from the measurement of LNB No. 2 [own research]

As can be seen from Fig. 10, the noise level drop from record No. 1, which was recorded on the hump yard, was significantly higher for LNB B2 than for LNB B1 at peak values in the range of over $25 \mathrm{~dB}(\mathrm{~A})$.

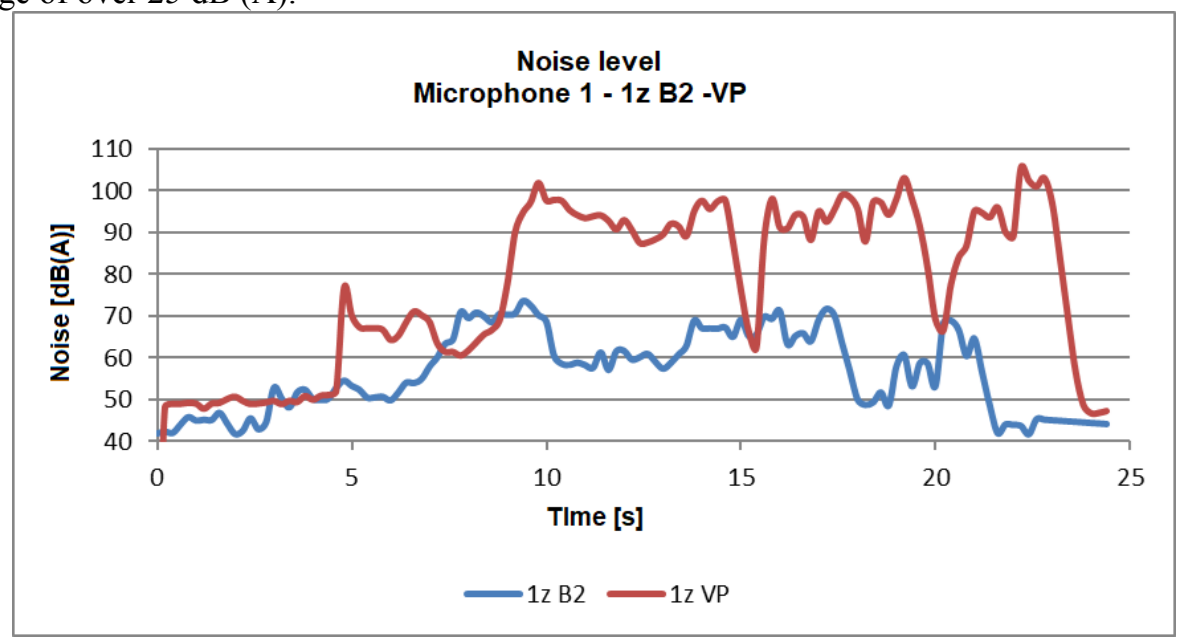

Fig. 10. Measurement of the noise level of record No. 1 microphone No.1 in the free field and after the attenuation with the LNB B2 [own research] 
When analyzing specific frequencies from the graph (Figure 11), it is obvious that at lower frequencies a more significant decrease compared to B1 is about $2 \mathrm{~dB}$. Frequencies above $12000 \mathrm{~Hz}$ do not exceed $20 \mathrm{~dB}$, and as with B1 from $17000 \mathrm{~Hz}$ from record No. 1, LNB B2 could completely attenuate.

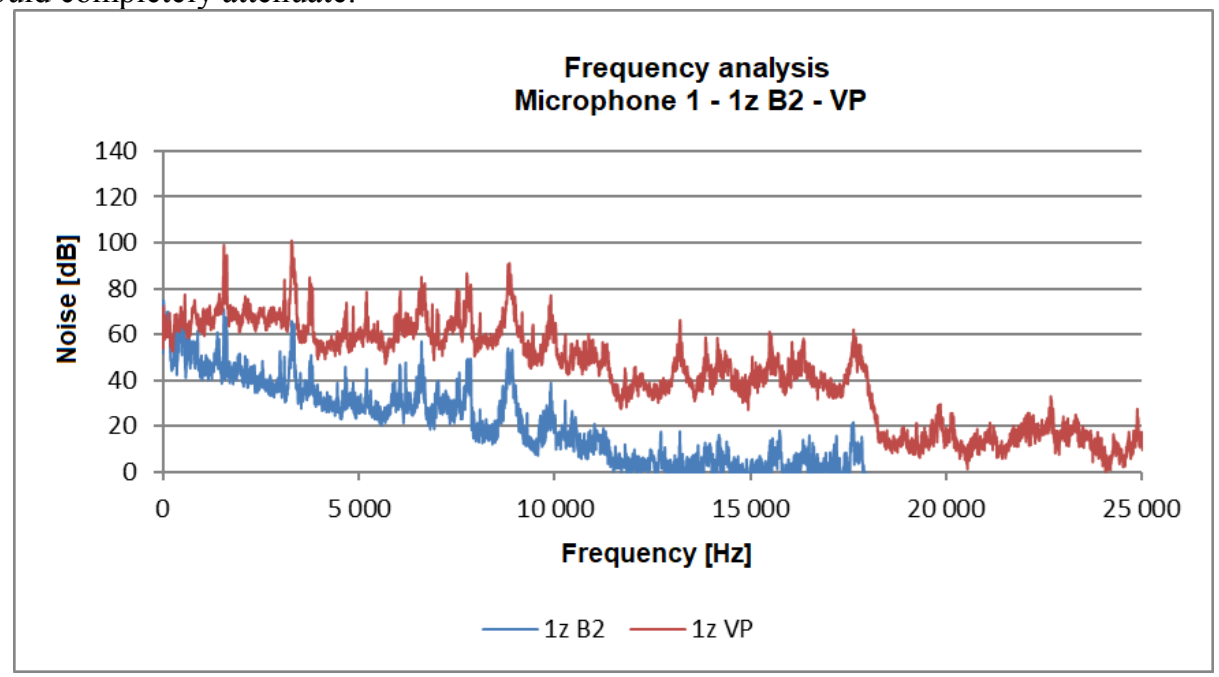

Fig. 11. Frequency analysis of noise recording No.1 of microphone No.1 in the free field and after dumping by LNB B2 [own research]

\section{Conclusions}

The main objective of the experimental verification of the acoustic properties of the proposed barriers was to assess the impact of the composition and location of the proposed materials. Both the low noise barriers had approximately the same dimensions - height and length. The shape and material of the covering was different. The observed attenuation acoustic effects of B2 were significantly higher than those of B1. This worse acoustic property can be attributed to a less suitable placement of the hard rubber layer on the STERED absorbing layer, which had a significantly more negative impact on the overall noise absorption of the low noise barrier.

\section{References}

1. D. Ďurčanská, et al., Environmental impact assessment of roads and motorways. Noise and Immissions from Road Transport (Žilina, 2002)

2. B. Salaiová, J. Mandula, M. Koval'aková, Selected chapters from road and railway constructions, Transport noise (Košice, 2001)

3. Catalog of Concrete Products of ŽPSV 6 (2013) http://www.zpsv.cz/ohlgroup/katalogy/ZPSV-katalog2013-lowres.pdf [cit. 06.06.2018] 